\title{
Adsorption of Cibacron Blue Dye from Aqueous Solutions onto HCL Treated Waste Biomass
}

\author{
B M W P K Amarasinghe, P A Jayasinghe and M Y Gunasekara
}

\begin{abstract}
Adsorption of Cibacron blue dye from aqueous solutions onto various biomass materials was studied. Batch experiments were conducted to determine the factors affecting adsorption. Fixed bed column experiments were performed and breakthrough curves were obtained to study practical applicability. Hydrochloric acid treated coir dust, rice husk, saw dust and tea waste are capable of binding appreciable amounts of cibacron blue dye from aqueous solutions. Cibacron dye showed the highest adsorption capacity and affinity in relation to coir dust under all the experimental conditions. Coir dust and granular activated carbon showed similar adsorption capacities. Adsorption capacity was highest at the solution $\mathrm{pH}$ range from 2 to 3 for all the adsorbents. The adsorbent to solution ratio, and the adsorbent particle size affect the degree of dye removal. Higher adsorption capacities were observed for smaller adsorbent particles. The equilibrium data were satisfactorily fitted to Langmuir and Freundlich isotherms. Langmuir constants showed highest dye uptake of $65,14,10$ and $5 \mathrm{mg} / \mathrm{g}$ for coir dust, saw dust, rice husk and tea waste respectively. Kinetic studies revealed that dye uptake was fast with 50\% or more of the adsorption occurring within the first 60 to 90 min of contact time. Column operations showed lower adsorption capacities than the batch operation for all the adsorbents except tea. Breakthrough curve results fit the linear Bed Depth Service Time model. The breakthrough time depends on the solution flow rate and initial dye concentration. Amounts of dye adsorbed in the column operations were $31,9,12,8 \mathrm{mg} / \mathrm{g}$ for coir dust, rice husk, saw dust and tea waste respectively. $83 \%$ of colour removal and $72 \%$ of Chemical Oxygen Demand (COD) removal efficiencies were achieved using $\mathrm{HCl}$ treated coir dust for the real textile wastewater samples containing a mixture of various dyes.
\end{abstract}

Key words: Adsorption, Packed bed, Breakthrough curve, Bed Depth Service Time.

\section{Introduction}

Industrial wastewater generated by the textile, paper, carpet and printing industries contains a high concentration of coloured organic compounds. This effluent is tough to be degraded because of the presence of dyes, which have complex aromatic molecular structures of synthetic origin. The color in dye house effluent from the textile industry is highly visible and affects aesthetics, water transparency and gas solubility in water. Most of the dye compounds are toxic and often carcinogenic. Release of wastewater containing dye compounds into water streams may pose a serious threat to public health and the aquatic community. Due to increased awareness of environmental aspects, many countries, including Sri Lanka, have imposed stringent environmental laws and more attention has been directed towards development of treatment methodologies. The textile industry in Sri Lanka rapidly developed over the last two decades and the effective method of treatment of coloured effluent has become an important issue today.
Removal of colour in textile effluents is achieved by numerous physical and chemical treatment techniques such as coagulation, flocculation, electro-flotation, membrane filtration, precipitation, ion-exchange, ozonization, electrolysis and adsorption [22],[33]. Even though some of these methods are effective, most of them suffer from short comings such as excess usage of chemicals, sludge disposal, expensive operating cost. Among several chemical and physical methods, adsorption is one of the effective techniques that has been successfully employed for colour removal from wastewater.

Activated carbon produced by carbonizing organic materials is the most widely used

\footnotetext{
Eng. Dr.(Mrs) B.M.W.P.K. Amarasinghe, B.Sc(Eng) (Moratuwa), MSc., PhD (UK), AMIESL, Senior Lecturer, Dept. of Chemical and Process Eng., University of Moratuwa

$\operatorname{Dr}$ (Ms) M.Y.Gunesekara, B.Sc(Eng), MEng(Moratuwa), PhD (UK), Senior Lecturer, Dept. of Chemical and Process Eng., University of Moratuwa

Ms. P.A. Jayasinghe, BSc(Eng) (Moratuwa) -Research student, Department of Chemical and Process Engineering, University of Moratuwa.
} 
adsorbent. Activated carbon has shown good dye adsorption capacities specially for catonic dyes [39], [18], [14], [12], [38], [25]. However; the high cost of the activation process limits it's use in wastewater treatment. Over the last few years a number of investigations has been conducted to test the low cost adsorbents for dye removal from waste water. Among the numerous waste biomass materials available in various parts of the world rice husk, saw dust, coir dust, dry tree leaves, tea or coffee waste and sunflower stalks have been widely experimented for adsorption of dyes [2], [3], [5], [7], [9], [10], [11], [13], [15], [16], [20], [23], [29], [30], [32], 35]. Industrial waste and Mineral waste have also been tested for their dye adsorption properties [1], [4], [8], [14], [19], [24], [28], [36], [38]. Among the low cost adsorbents tested for dye removal approximately $75 \%$ of the work has used waste biomass as an adsorbent [6], [26].

Disposal of the biomasses has become an obstacle to sustainable agriculture and the environment in most countries including Sri Lanka. Plant residues, which are mainly carbonaceous has the potential to be converted into adsorbent. This conversion could contribute to a reduction of the volume of waste, whist producing an adsorbent with a lower cost.

Degree of adsorption and rate of adsorption of dye molecules onto waste biomass depend on the physical and surface properties of adsorbent, dye properties and the operating conditions. Therefore, the effect of adsorbent properties and operating conditions on adsorption depends on the biomass-dyesystem and the knowledge of the same is important for decision making. Most of the previous work on low cost adsorbents is limited to batch experiments. Fixed bed columns are widely used in industry and adsorption isotherms obtained by batch experiments do not give accurate scale-up data in fixed bed systems.

This work investigates the potential of various waste biomass materials available in Sri Lanka as a low cost adsorbent for removal of colour in textile effluents. Adsorption of Cibacron Blue FR dye onto coconut coir dust, saw dust, rice husk and tea waste was investigated. The adsorbents were treated by hydrochloric acid to improve adsorption properties. Batch and fixed bed column studies were conducted to determine the factors affecting the adsorption process and to obtain data for industrial scale designing. The adsorption characteristics of low cost adsorbents were compared with that of commonly used adsorbent granular activated carbon.

\section{Methodology}

\subsection{Adsorbates}

Reactive Blue; namely Cibacron Blue FR dye a commonly used dye in Sri Lanka was used for all the experiments. Synthetic dye solutions were prepared by dissolving dye powder in distilled water to obtain required solution concentrations (50 - $200 \mathrm{mg} / 1)$.

\subsection{Adsorbent}

Coir dust (CD), rice husk $(\mathrm{RH})$ and saw dust (SD) were obtained from a local coir processing plant, a rice mill and a wood mill respectively. Tea waste (TW) was provided by the University of Moratuwa cafeteria. The adsorbent samples were first ground and sieved prior to their its use in experiments. The materials were then washed with distilled water and dried. The adsorbents were activated by impregnating them with the activation agent, $0.1 \mathrm{M}$ Hydrochloric acid (HC1), for 15 minutes. Then the samples were washed 2 to 3 times in tap water. Finally, the adsorbents were washed using distilled water and dried in an oven for 10 hours at $100{ }^{\circ} \mathrm{C}$. The fraction between $710 \mu \mathrm{m}$ to $1 \mathrm{~mm}$ was used for all the experiments except for the effect of size tests. The dried adsorbents were stored in sealed polythene bags.

Commercial granular activated carbon (GAC) provided by Haycarb Ltd. was used for the experiments for comparison purposes. Densities of the adsorbents were measured using the specific gravity bottle method.

\subsection{Experimental Analysis}

The dye concentrations in the solutions were determined by measuring the absorbance at maximum wavelength of dyes using a UV visible ERMA PHOTIC 100 spectrophotometerAbsorbance values were recorded at the wavelength of $680 \mathrm{~nm}$ for Cibacron Blue FR dye.

\subsection{Batch Experiments}

The batch adsorption experiments were conducted by adding $0.1 \mathrm{~g}$ to $1.5 \mathrm{~g}$ of adsorbents 
into beakers containing $100 \mathrm{ml}$ of $50 \mathrm{mg} / 1$ dye solution. The dye solutions were shaken at 100 rpm for $2 \mathrm{hrs}$ to approach equilibrium. Then the contents in the beakers were allowed to settle. The solution was filtered and the colour intensity of the filtrate was measured.

The $\mathrm{pH}$ studies were conducted by stirring 100 $\mathrm{ml}$ of dye solution with adsorbent over a range of $\mathrm{pH}$ values from 2 to 11 . Once the optimum $\mathrm{pH}$ was identified, the time required to reach equilibrium was measured for each adsorbent. Samples were collected from the top at $10 \mathrm{~min}$ intervals and the residual dye concentration analyzed. The experiments were continued until the equilibrium state was achieved.

The effect of the adsorbent particle size on adsorption was determined using particles over a range of 355-2000 um size.

Equilibrium isotherm experiments were conducted by shaking different quantities of adsorbent varying from $0.1 \mathrm{~g}$ to $1.2 \mathrm{~g}$ in $100 \mathrm{ml}$ of $50 \mathrm{mg} / 1$ dye solution each for a time period equal to the equilibrium time for that particular adsorbent. Blank runs, without adsorbent, were conducted simultaneously in similar conditions.

Experiments were conducted at room temperature of $30 \pm 2^{\circ} \mathrm{C}$. All the tests were repeated to observe repeatability.

\subsection{Packed Bed Experiments}

Column studies were conducted using a down flow technique in a $3 \mathrm{~cm}$ internal diameter glass column. The column was filled with a known weight of adsorbent to the required height (packing factor $=0.8$ ). The dye solution containing a known dye concentration adjusted to favourable $\mathrm{pH}$ was fed through the packed bed at a constant flow rate. Samples of the effluent leaving the column were collected periodically and analyzed for the dye concentration. Series of experiments were conducted to compare adsorbent types and to determine the effect of initial dye concentration $(50-200 \mathrm{mg} / 1)$, flow rate $(10-50 \mathrm{ml} / \mathrm{min})$ and bed height $(5-20 \mathrm{~cm})$ for coir dust.

\subsection{Textile Wastewater Treatment}

The packed bed column tests were conducted with the real wastewater containing various dyes, which was collected from a leading textile mill in Sri Lanka. The wastewater used was bluish black in colour. The adsorbent used was $\mathrm{HC} 1$ treated coir and a low flow rate of $12 \mathrm{ml} /$ $\min \left(2.83 \times 10^{-3} \mathrm{~m} / \mathrm{s}\right)$ was used to yield acceptable treated wastewater. The colour, $\mathrm{pH}$ and COD were compared between the untreated wastewater and the treated wastewater.

\section{Results and Discussion}

The adsorption behavior of the samples were studied by evaluating the colour removal efficiency calculated by equation (1),

$R_{e}=\frac{\left(C_{o}-C_{t}\right)}{C_{o}} * 100$

Where $C_{0}$ is the initial dye concentration in the aqueous solution, $C_{l}$ is the solution concentration after adsorption and $R_{e}$ is the percentage of colour removal. Bulk densities of the adsorbents determined as in section 2.2 and composition as reported in literature are shown in Table 1.

Table 1: Properties of adsorbents (dry basis).

\begin{tabular}{|c|c|c|c|c|c|}
\hline Adsorbent & \begin{tabular}{|c|} 
Solid \\
Density
\end{tabular} & $\begin{array}{l}\text { Cellu- } \\
\text { lose \% }\end{array}$ & $\begin{array}{l}\text { Hemi } \\
\text { Cellu- }\end{array}$ & $\underset{\%}{\operatorname{Lignin}}$ & $\begin{array}{l}\text { Moistu- } \\
\text { re con- } \\
\text { tent } \%\end{array}$ \\
\hline Coir Dust & 0.45 & 43 & $<20$ & 45 & $10-12$ \\
\hline Rice Husk & 0.73 & 32.24 & 21.34 & 21.44 & 6.62 \\
\hline Saw Dust & $\begin{array}{l}0.66- \\
0.88\end{array}$ & $40-45$ & $20-35$ & $25-35$ & 7.95 \\
\hline Tea Waste & 0.49 & \multicolumn{2}{|c|}{$4-7$} & $5-6$ & 5.41 \\
\hline GAC & 2.1 & - & - & - & - \\
\hline
\end{tabular}

\subsection{Effect of Adsorbent Dosage}

Figure 1 shows the percentage colour removal as a function of adsorbent dose for the range of adsorbents used.

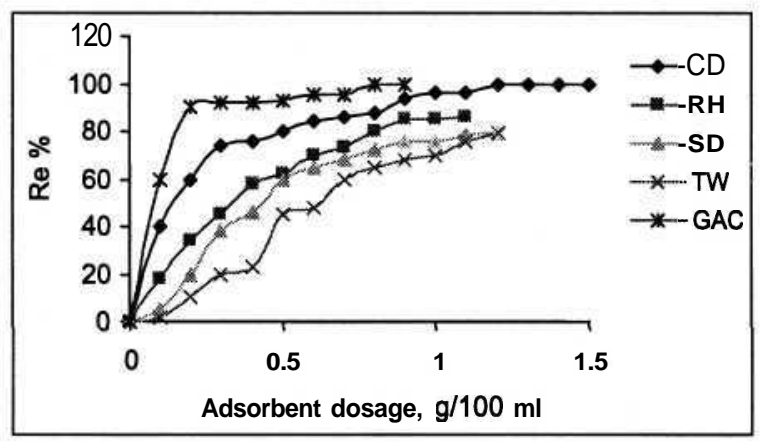

Figure 1: Effect of adsorbent dosage Co $50 \mathrm{mg} / \mathrm{l}$, pH 2-3, Particle size 710 micron 
Results show percentage adsorption increases with the adsorbent dose for all the adsorbents. The number of available adsorption sites increases by increasing the adsorbent dose and therefore, results in the increase of removal efficiency. However, results show that the effect of adsorbent dose on percentage removal decreases at higher doses $(>0.8 \mathrm{~g} / 100 \mathrm{ml})$. Percentage removal of dye was in the order Activated carbon $(\mathrm{GAC})>$ Coir dust $(\mathrm{CD})>$ Rice husk $(\mathrm{RH})>$ Saw dust (SD)> Tea waste. Tea waste shows lowest \% removal at low adsorbent doses but increases to a value similar to saw dust at high doses.

Untreated material showed no significant change in colour. This indicates that washing of adsorbents with $\mathrm{HCl}$ results in change in surface charge of the adsorbent surface from negative to positive, and thus, will improve their adsorptive properties for anionic species.

\subsection{Effect of $\mathrm{pH}$}

The $\mathrm{pH}$ value of the dye solution plays an important role in the adsorption process and particularly on the adsorption capacity. The removal of dyes as a function of $\mathrm{pH}$ is shown in Figure2.

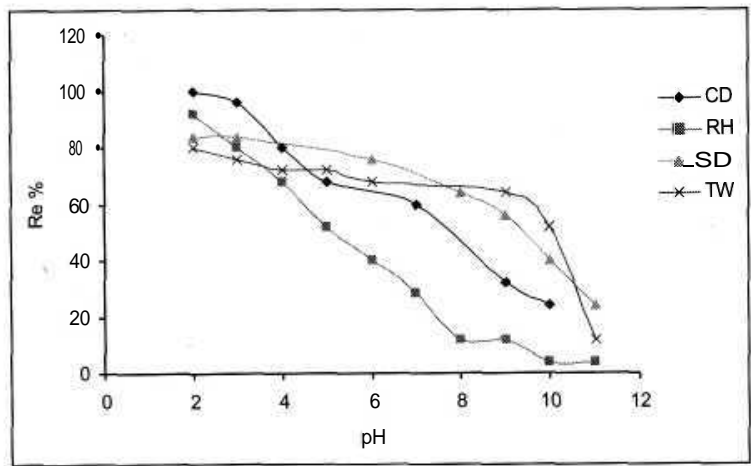

Figure 2: Effect of pHon \% removal of dye adsorbed on various $\mathrm{HCl}$ treated adsorbents.

The adsorption of dyes onto all four adsorbents was found to be much higher in the acidic $\mathrm{pH}$ range of 2-4 than those in neutral and alkaline conditions. This phenomenon can be explained by the surface charge of the adsorbent and the $\mathrm{OH}$ - ions present in the solution. At higher $\mathrm{pH}$ anionic dyes compete with $\mathrm{OH}$ - ions and hence lower the adsorption. Zeta potential of plant materials is a strong function of $\mathrm{pH}$. At higher $\mathrm{pH}$ surface is highly negative and hence attracts less anions. As the $\mathrm{pH}$ of the adsorption solution was lowered, the positively charged adsorption sites increased. This would attract the negatively charged functional groups of dye.

\subsection{Effect of Particle Size}

The adsorption capacity depends on the surface properties of the adsorbent. Specific surface area available for solute - surface interaction, which is accessible to the solute is the most important parameter.

The decrease in particle size led to an increase in the surface area available for adsorption and hence an increase in the removal capacity. The results showed that for coir dust particles of mean size 2000, 1400, 1000 and $710 \mu \mathrm{m}$ the percentage of dye removal is $50,70,80$ and 100 respectively. These results show agreement with the results reported in the literature for fly ash, tea waste, activated carbon and coir pith [7],[27],[39].

\subsection{Effect of Contact Time}

Effect of contact time on adsorption is shown in Fig. 3. The colour removal efficiency increased with contact time and reaches equilibrium after a certain time. All the adsorbents showed very rapid initial uptake followed by a slower process. This behaviour suggests the occurrence of a rapid external mass transfer followed by a slower internal diffusion process which may be the rate determining step. Coir dust exhibited an equilibrium time of 120 minutes to achieve $100 \%$ dye removal. $75 \%$ of colour removal was achieved within 60 mins. Such short times coupled with high removals indicate a high degree of affinity for the dye group. Optimum contact time for rice husk saw dust and for tea waste was found to be 240 minutes. Rice husk removed colour up to $92 \%$ efficiently while saw dust and tea waste exhibited relatively poor removal efficiency of $84 \%$ with the equilibrium time of 240 minutes.

\subsection{Adsorption Isotherms}

Several equilibrium models have been developed to describe adsorption isotherm relationships. Langmuir and Freundlich adsorption isotherm models are widely employed.

For solid-liquid systems, the Langmuir adsorption isotherm is expressed as;

$x / m=\frac{Q b C e}{1+b C e}$ 
Table 2: Linear regression data for Freundlich and Langmuir isotherms on dye removal using various

\begin{tabular}{|l|l|l|l|l|l|l|}
\hline \multirow{2}{*}{ Adsorbent } & \multicolumn{3}{|c|}{ Freundlich Isotherm } & \multicolumn{3}{c|}{ Langmuir Isotherm } \\
\cline { 2 - 7 } & $n$ & $\mathrm{~K}$ & $\mathrm{R}^{2}$ & $\mathrm{Q}(\mathbf{M g} / \mathrm{G})$ & $\mathbf{B}$ & $\mathbf{R}^{2}$ \\
\hline Coir Dust & 0.85 & 1.2 & 0.9879 & 65.36 & 0.0151 & 0.9975 \\
Rice Husk & 0.43 & 1.9 & 0.9630 & 10.31 & 0.0945 & 0.9855 \\
Saw Dust & 0.56 & 1.0 & 0.8905 & 13.93 & 0.0336 & 0.9462 \\
Tea Waste & 0.30 & 1.85 & 0.8618 & 5.17 & 0.2479 & 0.8275 \\
Gac & 0.57 & 5.4 & 0.7979 & 45.45 & 0.0948 & 0.8516 \\
\hline
\end{tabular}

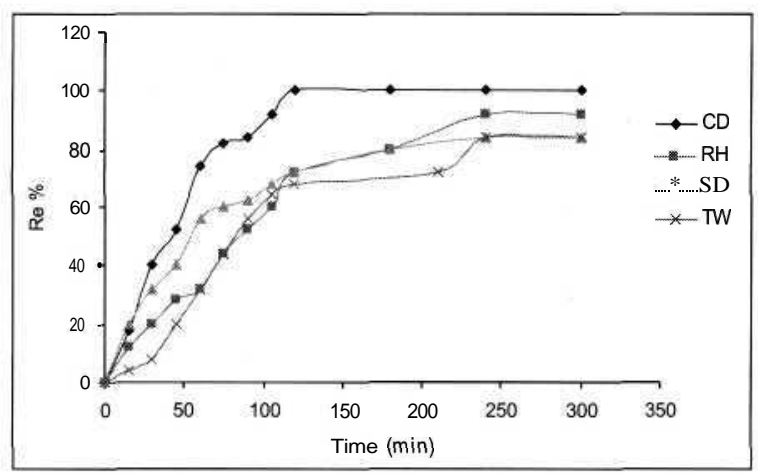

Figure 3: Kinetic studies for various types of $\mathrm{HCI}$ treated adsorbents at $30^{\circ} \mathrm{C}$, Co $50 \mathrm{mg} / \mathrm{I}, \mathrm{pH} \mathrm{2-3,}$ Particle size 710 micron

The linear form of the Langmuir isotherm is given by equation (3),

$\frac{1}{x / m}=\frac{1}{b Q} \frac{1}{C e}+\frac{1}{Q}$

The Freundlich equation is an empirical expression and is expressed as;

$x / m=K(C e)^{n}$

The linear form of the Freundlich isotherm is given by equation (5),

$\log x / m=n \log C e+\log K$

Where $x / m$ is the amount of solute adsorbed per weight of adsorbent $(\mathrm{mg} / \mathrm{g})$ at equilibrium, $C e$ is the solution dye concentration at equilibrium (ppm), $Q$ is the Langmuir isotherm constants also called monolayer capacity $(\mathrm{mg} / \mathrm{g})$ and $b$ is the Langmuir constant, $K$ and $n$ are Freundlich constants related to adsorption capacity and adsorption intensity.

Langmuir and Freundlich isotherm constants for the adsorption of Cibacron Blue (CB) dye onto each of the adsorbents are presented in Table 2. The correlation coefficient $\left(R^{2}\right)$ close to 1 indicates that the adsorption process confirms to both Langmuir and the Freundlich adsorption isotherms. Langmuir isotherm has a slightly better fitting model than Freundlich thus, indicating to the applicability of monolayer coverage of the dye particle on the surface of adsorbent. The value of $n$ obtained from Freundlich isotherm, for adsorption of most organic compounds by activated carbon is $<1$. $0<\mathrm{n}<1$ indicates the adsorption is favourable. Coir dust shows highest the adsorption capacity $(\mathrm{Q})$ and affinity $(n)$ when compared to the other adsorbents.

\subsection{Packed Bed Studies}

Packed bed experimental data are essential for industrial-scale adsorber design. The adsorption isotherms obtained by batch experiments do not give accurate scale-up data in fixed bed systems. Therefore practical applicability of low cost adsorbents was also ascertained in column operations.

Figure 4 shows breakthrough curves obtained for the adsorption of Cibracorn blue onto four types of adsorbents. The area above the breakthrough curve is a measure of the bed capacity (BC in $\mathrm{mg}$ ) and is given by the following equation (6). [34].

Then, $B C=G \int_{0}^{T t}(C o-C) d T$

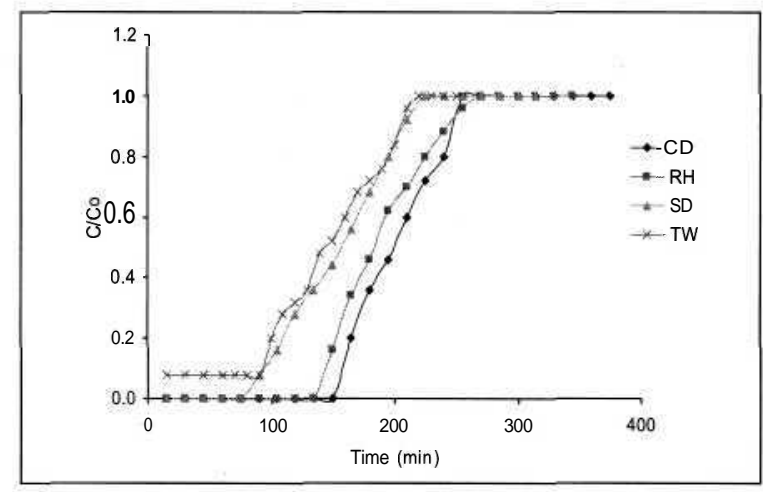

Figure 4: Breakthrough curves for various types of HCI treated adsorbents at $30^{\circ} \mathrm{C}$, Co $50 \mathrm{mg} / \mathrm{I}, \mathrm{pH} \mathrm{2-3,}$ Particle size 710 micron, Bed height $10 \mathrm{~cm}$, Flow rate $20 \mathrm{ml} / \mathrm{min}$ 
Where, $\mathrm{G}$ is the inlet solution flow rate $\mathrm{ml} / \mathrm{min}$, $\mathrm{CO}$ and $\mathrm{C}$ are the initial concentration of solute in $\mathrm{ppm}$ and solute concentration at time $\mathrm{T}$ in ppm.

Adsorption capacities in the fixed bed column were calculated using equation (6) and listed in the Table 3. For the comparison of data, the equilibrium capacities obtained from batch experiments are also included in the same table. Adsorption capacities and breakthrough times are in the order coir dust>rice husk>saw dust $>$ tea waste. This order of adsorption capacities are in agreement with the batch adsorption experiments shown in Fig 1.

Table 3: Comparison of bed and batch adsorption capacity

\begin{tabular}{|l|c|c|}
\hline Adsorbent & $\begin{array}{c}\text { Packed bed } \\
\text { Capacity (mg/g) }\end{array}$ & $\begin{array}{c}\text { Equilibrium } \\
\text { batch Capacity } \\
\text { (mg/g) }\end{array}$ \\
\hline Coir Dust & 30.61 & 65.36 \\
Rice Husk & 9.30 & 10.31 \\
Saw Dust & 11.57 & 13.93 \\
Tea Waste & 8.02 & 5.17 \\
\hline
\end{tabular}

For all the adsorbents except tea waste, the bed capacities are lower than that of the batch system. In batch experiments the mixture was shaken continuously and good interaction between the solid and solute was achieved. In the fixed bed, adsorbent is packed in the column and surface of the solid particles are in contact with each other and therefore results in a less solid-solute interaction. Further, liquid channeling which results in poor solid-metal ion contact and less residence time may therefore occur in the column. Therefore bed adsorption capacities are lower compared to batch operation. Therefore, the batch system may provide better interaction between dyes and adsorbent than in the column system.

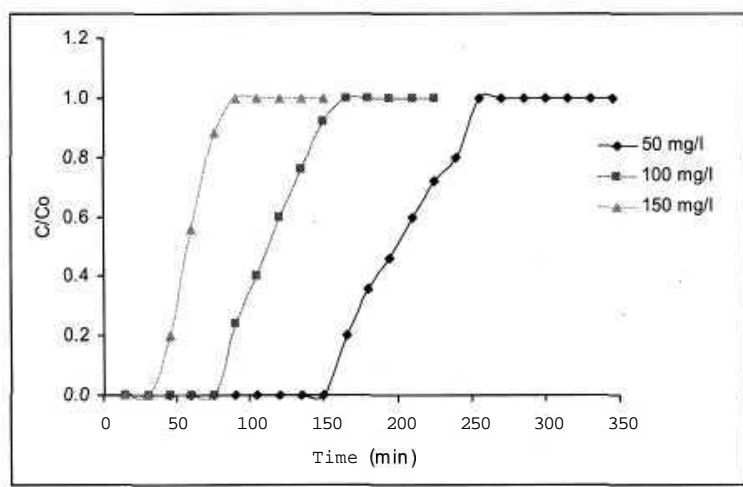

Figure 5: Effect of various initial dye concentrations Co, for the system; packed bed height $10 \mathrm{~cm}, \mathrm{pH} 2-3$ Flow rate $20 \mathrm{ml} / \mathrm{min}$, Coir dust particle size 710
The effect of initial dye concentration on the breakthrough curve for coir dust is shown in Fig. 5.

The breakthrough time decreases with the initial dye concentration. Therefore, the volume of effluent that a fixed mass of adsorbent can purify decreases with the effluent concentration.

The effect of varying the flow rate was investigated for coir dust and the breakthrough curves are presented in Figure 6. It is evident from this figure that as the flow rate increased, the service time was shortened and hence the volume treated until breakthrough. The breakthrough time for $\mathrm{C} / \mathrm{C}_{0}=0.2$ for 10,20 and $30 \mathrm{ml} / \mathrm{min}$ flow rates are 360, 160 and $75 \mathrm{mins}$ respectively. This high reduction in breakthrough time at high flow rates is due to the short residence time of the dye molecules in the column. A similar trend was observed for adsorption of basic dyes onto activated carbon and zeolite by Markovska [17].

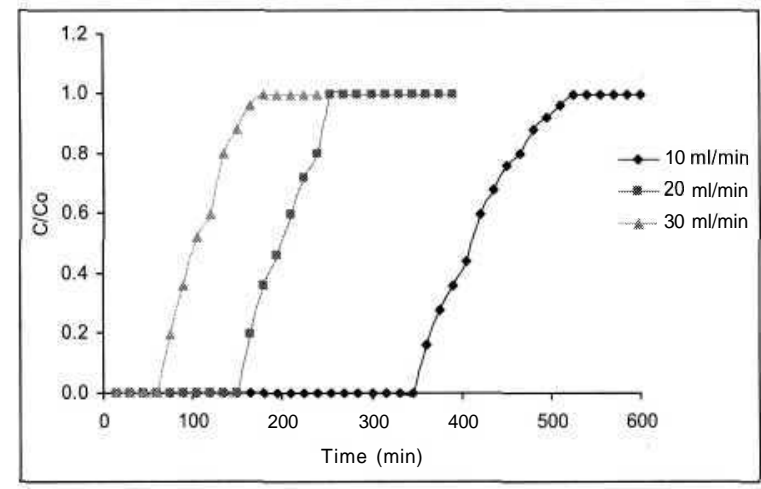

Figure 6: Effect of various flow rates at a bed height $10 \mathrm{~cm}, \mathrm{pH} \mathrm{2-3,} \mathrm{Co} 50 \mathrm{mg} / \mathrm{I}, \mathrm{HCI}$ treated Coir Dust particle size 710 micron

Figure 7 shows the breakthrough curves of different bed depths at a constant flow rate.

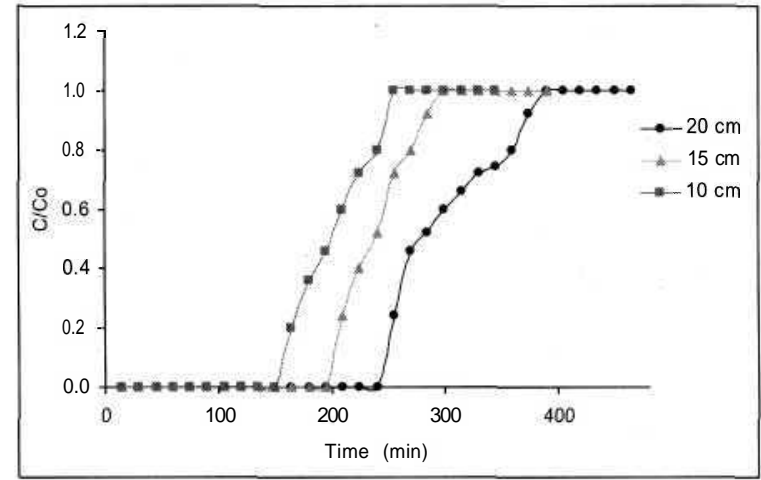

Figure 7: Effect of various bed heights at aflow Rate 20 ml/min, pH 2-3, Co 50 mg/I, HCI treated Coir dust particle size 710 micron 
The variation in concentration profile was due to the relatively large adsorption zone. The rate at which the adsorption zone travels through the bed decreases with the depth, suggesting that beds of an increased height may be required for dye adsorption. This phenomenon occurs in the adsorption of dyestuffs because of their large molecular structure, resistance to internal diffusion was much higher than smaller molecules. This resulted in the dye molecules not having enough contact time to diffuse from the surface of the particle to the adsorption sites. However, most research carried out on the adsorption of dyes showed breakthrough curves similar in trend to the profiles reported here [21], [39].

\subsection{Bed Depth Service Time (Bdst) Model}

The Bed Depth Service Time (BDST) method, based on a model proposed by Bohart and Adams that was later Linearized by Hutchins, (1974) has been reported as offering the simplest approach and most rapid prediction of adsorber performance [27].

This model proposed a relationship between bed depth, Z, and the time taken for breakthrough to occur, and it assumes that the adsorption rate is proportional to both the residual adsorbent capacity and the remaining adsorbate concentration. According to Bohart and Adams, the BDST curves are described by,

$\ln \left[\frac{\mathrm{Co}}{\mathrm{L}}-1\right]=\ln [\exp (K N o Z / V)-1]-K C o T$

Rearranging by Hutchins;

$$
T=\frac{N o}{C o V} Z \frac{1}{K C o} \ln \left[\frac{C o}{C b}-1\right]
$$

Where,

$$
\begin{aligned}
T & =\text { Service time. } \\
Z & =\text { Depth of adsorbent bed. } \\
V & =\text { Linear flow rate. } \\
K & -- \text { Adsorption rate constant. } \\
N o & =\text { Adsorptive capacity. }
\end{aligned}
$$

The BDST equation is easier to use in its simplified form;

$T=a Z-b$

Where,

$$
\begin{aligned}
& a=\frac{N O}{C o V} \\
& b=\frac{1}{K C o} \ln \left[\frac{C o}{C b}-1\right]
\end{aligned}
$$

The bed depth verses service time plots for coir dust at different flow rates and different dye concentrations are shown in Figs. 8 and 9 respectively. The breakthrough point for this study was fixed at $10 \%$ of the feed concentration.

Figure 9 shows BDST plots for the adsorption of Cibacron Blue dye onto coir dust at $10 \%$ breakthrough for various inlet dye concentrations. High slope at lower inlet concentrations indicates that bed performs better with a high service time at low flow rates.

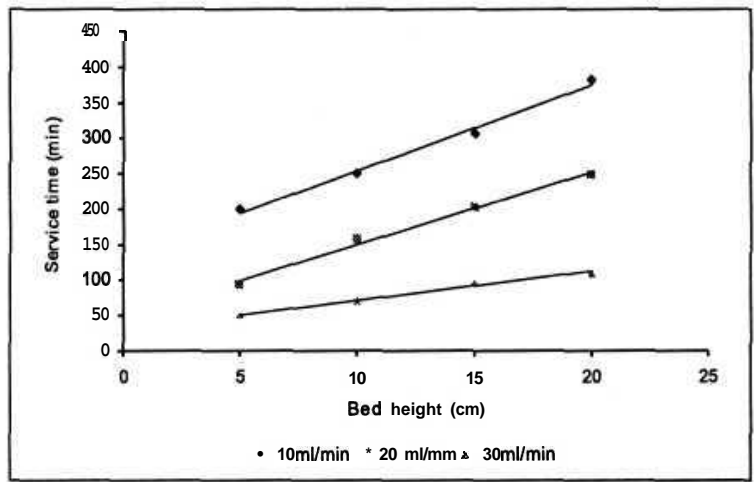

Figure 8: BDST plots for various flow rates $\mathrm{HCI}$ trated Coir Dust at $30^{\circ} \mathrm{C}, \mathrm{pH} 2-3$, Particle size 710 micron, Bed height $10 \mathrm{~cm}, \mathrm{C}_{\mathrm{o}} 50 \mathrm{mg} / \mathrm{I}$

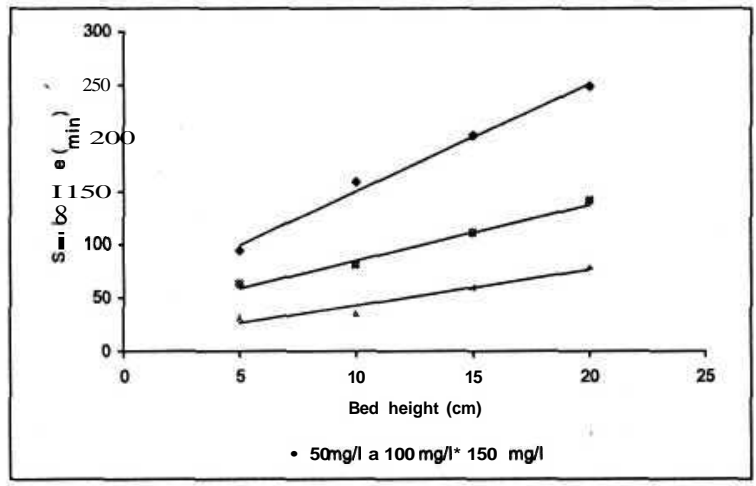

Figure 9: BDST plots for various dye concentrations HCI treated Coir Dust at $30^{\circ} \mathrm{C}, p H 2-3$, Particle size 710 micron, Bed height $10 \mathrm{~cm}$, Flow rate $20 \mathrm{mV} / \mathrm{min}$

\subsection{Real Textile Wastewater Treatment}

The colour removal of the real textile wastewater was measured at a wavelength of $560 \mathrm{~nm}$. The comparison of values of absorbance, $\mathrm{pH}$ and COD are shown in Table 4. The experiments showed that the column was rapidly saturated at $20 \mathrm{ml} / \mathrm{min}$ flow rate. This is due to the competition of several organic matters to be adsorbed. Thus the lower flow rate $12 \mathrm{ml} / \mathrm{min}$ was used to treat the real textile wastewater. The results showed that the quality 
Table 4: Qualities of wastewater and treated water

\begin{tabular}{|l|c|c|c|c|}
\hline \multicolumn{1}{|c|}{ Parameter } & Waste water & Treated waste water & CEA Standard limit & \% Removal \\
\hline $\begin{array}{l}\text { Absorbance } \\
(560 ~ \mathbf{~ m})\end{array}$ & $\mathbf{0 . 1 8}$ & $\mathbf{0 . 0 3}$ & - & $\mathbf{8 3 . 3 3}$ \\
pH & $\mathbf{9 . 4}$ & $\mathbf{6 . 9}$ & $6.5-8.5$ & - \\
COD mg/1 & $\mathbf{7 9 0}$ & $\mathbf{2 2 0}$ & $\mathbf{2 5 0}$ & $\mathbf{7 2 . 1 5}$ \\
\hline
\end{tabular}

of treated wastewater is within the standard limits of industrial effluents.

\section{Conclusions}

Coir dust (CD), rice husk (RH), saw dust (SD) and tea waste (TW), treated with hydrochloric acid are effectively utilized as adsorbents for the removal of cibacron blue dye from textile effluents. Adsorption efficiency depends on the source of the raw material, its preparation methodology and operating conditions. Removal of dye is at highest around solution $\mathrm{pH}$ 2 to 3 . Coir dust showed highest adsorption capacity and affinity under all the experimental conditions. Percentage removal of dye was in the order $\mathrm{GAC}>\mathrm{CD}>\mathrm{RH}>\mathrm{SD}>\mathrm{TW}$. However, Langmuir constants, $\mathrm{Q}$, values and column adsorption capacities were in the order $\mathrm{CD}>\mathrm{SD}>\mathrm{RH}>\mathrm{TW}$. Adsorption isotherms fit to the Langmuir and Freundlich isotherms. Fixed bed column results show similar trend as batch experiments. However, adsorption capacities are lower compared to batch experiments. The breakthrough through times fits the linear bed depth service time (BDST) model.

These investigations are quite useful in developing an appropriate technology for wastewater treatment. However, the adsorption characteristics largely depend on the type of dye and therefore should be tested for other dye types. The adsorbents under study are suitable for both decolourizing and adsorbing of organic molecules of solution and it could be efficiently and economically applied to clean the wastewater of the textile industry. Regeneration of biomass is not required as the biomasses are available at low or no cost. Used biomass waste can be disposed by incineration.

\section{Acknowledgement}

This study was supported by the University of Moratuwa research grant. The authors wish to thank Ms.SMND Martino for her support in laboratory work.

\section{References}

1. Albanis T.A. et al, Removal of dyes from aqueous solutions by adsorption on mixtures of fly ash and soil in batch and columns techniques. Vol 2, no 3, pp 237-244, 2000.

2. Amarasinghe BMWPK, De Silva IMBM, Use of waste biomass for colour removal from textile effluent, SLASS, Proceedings of the 57th Annual sessions, Part I-Abstracts, C150, 26 Nov.- 01 Dec, Colombo, 151, 2001.

3. Amarasinghe BMWPK, Gangodavilage N, Adsorbents from waste biomass: Production and Application, 7th World Congress of Chemical Eng., Glasgow, July.10-14, 2005.

4. Armagan B, Turan M, Celic M, Equilibrium studies on the adsorption of reactive azo dyes into zeolite, Desalination, 170, 33-39, 2004.

5. Asfour H.M. et.al, Colour removal from textile effluents using harwood sawdust as an adsorbent, J.Chem.Tech. Biotechnology, 35A, 2835., 1985.

6. Babu, B.V. and V.Ramakrishna, "An Approach for Ranking of Adsorbents Based on Method of Preparation and Isotherm Fitting", Proceedings of International Symposium \& 56th Annual Session of IIChE (CHEMCON-2003), Bhubaneswar, December 19-22, 2003.

7. Balasubramanian, M.R. and Muralisankar, I, Utilization of fly ash and tea waste ash as decolourising agents for dye effluents, Indian Journal of Technology, 25, 471-474, 1987.

8. Ceyhan $\mathrm{O}$ and Baybas D, Adsorption of some textile dyes by Hexadecy ltrimethy lammonium Bentonite, Turk J Chem, 25, 193-200, 2001.

9. Chio, M. S., Ho, P. Y. and Li, H .Y, Adsorption behaviour of dye AAVN and RB4 in acid solutions on chemically cross linked chitosan beads, J.Chin.Inst. Chem. Engrs, 34, 6, 625-634, 2003.

10. Inthorn D et.al, Decolorization of basic, direct and reactive dyes by pre-treated narrow-leaved cattail, Bioresource Technology, 94, 299-306, 2004.

11. Joseph, A.L, Removing acid dyes from textile wastewater using biomass for decolorization, American dye stuff reporter, August, 17-21., 1994. 
12. Kannan N. and Meenakshisundaram M, Adsorption of congo red on various activated carbons: a comparative study, Water, air and soil pollution, Vol. 138, NO1-4, July, 289-305., 2002.

13. Khalil, L.B. and Girgis, B.S., Adsorption characteristics of activated carbon obtained from rice husks by treatment with phosphoric acid, Fuel science and Technology, 13, 4, 131-136, 1994.

14. Lin, S.H., Adsorption of disperse dyé by various adsorbents, J.Chem. Tech. Biotechnol, 58, 159-163, 1993.

15. Lodha, A. et. al., Sorption of methylene blue on to rice husk, IJEP, 17, 9, 675-679, 1997.

16. Malik P.K., Use of activated carbons prepared from sawdust and rice husk for adsorption of acid dyes: A ase study of acid yellow 36, Dyes and Pigments, Vol 56, No 3 March. 239-249,2003.

17. Markovska, L et.al., Solid diffusion control of the adsorption of basic dyes onto granular activated carbon and natural zeolite in fixed bed columns, J.Serb.Chem.Soc, 66, $7,463-475,2001$

18. Marmagne $\mathrm{O}$ and Coste $\mathrm{C}$, Color removal from textile plant effluents, American Dyestuff Reporter, 15-22,1996.

19. Mckay G., Blair H.S. and Gardener J.R., Adsorption of dyes onto Chitin in Fixed bed columns and batch adsorbers, J. of Applied Polymer Science, Vol.29, 1499-1514, 1984.

20. Nakamura T, et.al, Decolorization of Acidic Dye by Charcoal from coffee grounds, J. of Health science, 49(6), 520-523, 2003

21. Netpradit, S., Thiravetyan, P. and Towprayoon, Evaluation of metal hydroxide sludge for reactive dye adsorption in a fixed bed column system, Water research, 38, 71-78, 2004.

22. O'neill C. et.al., Colour in textile effluents-sources measurement, discharge consents and simulation: review, J. of. Chem. Tech. and BioTech. 74, 1009-1018, 1999.

23. Rahman and B. Saad, Utilization of Guava Seeds as a Source of Activated Carbon for Removal of Methylene Blue from Aqueous Solution, Vol. 5, No. 1, 008 - 014, 2003.

24. Ramakrishna K.R. and Viraraghavan, T., Dye removal using low cost adsorbents, Wat.Sci. Tech, 36, 2-3, 189-196, 1997.

25. Reife A. and Freeman H., Environmental Chemistry of dyes and pigments, John wiley and sonc Inc, 1996.

26. Sanghi R. and Bhattacharya B., Review on decolorisation of aqueous dye solutions by low cost adsorbents, Coloration Technology, Vol. 118, No 5, 256-269, 2002.
27. Santhy, K. and Selvapathy, P., Removal of reactive dyes from wastewater by adsorption on coir pith activated carbon, Bioresource technology XXX, 2005.

28. Sapci Z, ustun B, The removal of color and COD from textile wastewater by using Waste Pumice, EJEAFche, 2(2), ISSN 1579-4377, 2003.

29. Shi, W., Xu, X. and Sun, G., Chemically modified sunflower stalks as adsorbents for color removal from textile waste water, J. of app. Polymer Sc. 71, 1841-1850, 1999.

30. Shukla, A. et. al., The role of sawdust in the removal of unwanted materials from water, Journal of Hazardous materials, B 95, 137-152, 2002.

31. Sun, G. and Xu, X., Sunflower stalks as adsorbents for color removal from textile waste water, Ind. Eng. Chem. Res., 36, 3, 1997.

32. Thiravetyan P. et.al., Removal of metal complex dyes from synthetic textile wastewater by ricehusk, Env. Biotechnology: Biotechnology applications for treatment and Utilisation of Industrial wastes, April 15-17, New Zeeland 477484, 2002.

33. Thimothy, R.D. and Uhrich, K.D., New developments for (textile mill) wastewater treatment, The American dyestuff reporter, June, 1988.

34. Treybal, R.E., Mass transfer operations, McGrawHill Companies; 3rd edition, pg 565-642., 1980.

35. Vadivelan V, and Vasanth Kumar K., Equilibrium kinetics, mechanism, and process design for the sorption of methylene blue onto rice husk, J Colloid Interface Sci. 2005 Jun 1;286(1):90-100, 2005.

36. Vanjara, A.K., Colour removal from textile effluent using refuse derived fuel as an adsorbent, Indian Journal of Technology, 5, 53-55, 1998.

37. Viraraghavan, T. and Ramakrishna, K.R., Fly ash for colour removal from synthetic dye solutions, water Qual. Res. J. Canada, 34, 3, 505-517, 1999.

38. Voudrias E, Fytianos K and Bozani E, SorptionDesorption isotherms of dyes from aqueous solutions and wastewaters with different sorbent materials, Global Nest the Int. J., Vol 4, No 1, 7583, 2002.

39. Walker G.M., Weatherley L.R., Adsorption of acid dyes onto granular activated carbon in fixed beds, Wat.Res. Vol 31, No 8, 2093-2101, 1997.

40. http://www.boi.lk/pdf/env.pdf

41. http://www.ifc.org/ifcext/enviro.nsf/ AttachmentsByTitle/gui_textiles_WB/\$FILE/ textile_PPAH.pdf 